\title{
https://doi.org/10.30853/filnauki.2020.5.24
}

\section{Ван $\mathrm{Ha}$}

Преодоление семантических оппозиций в семиотически сложных художественных текстах

В статье была поставлена цель - рассмотреть явление семантической оппозиции, проанализировать примеры преодоления семантических оппозиций в художественном тексте, а также выявить способы формирования текстового семантического поля. Научная новизна исследования состоит в установлении специфики преодоления оппозиций в семиотически сложных текстах. В результате исследования обнаружено, что при преодолении семантических оппозиций в художественном тексте формируются неповторимые текстовые семантические поля, причѐм как под влиянием сознания автора, так и бессознательно. Преодоление семантических оппозиций служит уточнению смысла художественного произведения, раскрытию его идеи, увеличению его содержательной и эмоциональной информативности.

Адрес статьи: www.gramota.net/materials/2/2020/5/24.html

\section{Источник}

Филологические науки. Вопросы теории и практики

Тамбов: Грамота, 2020. Том 13. Выпуск 5. С. 131-134. ISSN 1997-2911.

Адрес журнала: www.gramota.net/editions/2.html

Содержание данного номера журнала: www.gramota.net/materials/2/2020/5/

\section{( Издательство "Грамота"}

Информация о возможности публикации статей в журнале размещена на Интернет сайте издательства: www.gramota.net Вопросы, связанные с публикациями научных материалов, редакция просит направлять на адрес: phil@gramota.net 
УДК 811.161.1

https://doi.org/10.30853/filnauki.2020.5.24

Дата поступления рукописи: 01.04.2020

В статье была поставлена цель - рассмотреть явление семантической оппозиции, проанализировать примеры преодоления семантических оппозиций в художественном тексте, а также выявить способы формирования текстового семантического поля. Научная новизна исследования состоит в установлении специфики преодоления оппозиций в семиотически сложных текстах. В результате исследования обнаружено, что при преодолении семантических оппозиций в художественном тексте формируются неповторимые текстовые семантические поля, причём как под влиянием сознания автора, так и бессознательно. Преодоление семантических оппозиций служит уточнению смысла художественного произведения, раскрытию его идеи, увеличению его содержательной и эмоциональной информативности.

Ключевые слова и фразы: семантическая оппозиция; преодоление оппозиции; текстовое семантическое поле; семиотический сложный текст; художественный текст.

\section{Ван На}

Российский университет дружбы народов, г. Москва

helenvanna@yandex.ru

\section{Преодоление семантических оппозиций в семиотически сложных художественных текстах}

Текст является сложной семиотической системой, находящейся в зависимости от творческого замысла автора. Как отмечает Ю. М. Лотман, текст представляет собой «систему разнородных семиотических пространств» [7, с. 7], в связи с чем в него могут быть включены различные семиотические единицы, вступающие в многообразные сочетания друг с другом. В качестве примера семиотически сложных текстов выступают, прежде всего, художественные тексты, которые надстраиваются над системой общеупотребительного языка и не удовлетворяются оппозициями, которые существуют в естественном языке.

Каждому тексту, в частности художественному, свойствен «внутренний механизм семантических отношений» [10, с. 109], то есть в нем формируются оригинальные, ни на что не похожие, обусловленные индивидуальными особенностями автора смыслы, которые проявляются только в контексте. Эти контексты создают новые значения, а в результате сформированных новых значений преодолевается (ослабляется, нейтрализуется или вообще заменяется) семантическая оппозиция естественного языка, а также формируется новая, авторская, значимая именно для данного текста оппозиция. Осуществлению данного смыслового приращения в тексте, по мнению Л. А. Новикова, в значительной степени способствует механизм «импликации - отношение если A, то В» или, наоборот, если В, то А, внутри которого одни элементы противостоят другим «по принципу оппозиции, что создает полевую структуру текста» [8, с. 557], или так называемое текстовое семантическое поле.

Семиотикой художественного текста занимаются многие исследователи: С. А. Архипова и Л. Ю. Буянова [1], М. Н. Крылова [6], Г. А. Химич [12] и др. Однако при этом чаще всего анализируются какие-либо семиотические единицы и их функционирование в художественном тексте, а анализ преодоления автором художественного текста семантических оппозиций в связи с его семиотической сложностью не становится предметом рассмотрения. Актуальность данного исследования определяется тем, что в процессе анализа преодоления семантических оппозиций выявляются намерения автора текста и устанавливаются способы реализации данных намерений; становится ясной роль контекста в преодолении семантических оппозиций; появляется представление о целостном, комплексном характере художественного текста, о формируемых в его пределах авторских семантических полях.

Цель настоящего исследования - рассмотреть, каким образом формируется текстовое семантическое поле, выяснить, как в нем происходит развитие контекстуальных значений, в которых преодолеваются оппозиции естественного языка. Задачи: рассмотрение семантических оппозиций в художественных текстах и выявление авторских способов их преодоления, а также анализ формирования в итоге текстовых семантических полей. В ходе исследования использовались методы лингвистического анализа художественного текста и интерпретации результатов данного анализа, а также методы наблюдения и синтеза. Теоретическая база исследования включает труды О. И. Валентиновой, Ю. М. Лотмана, Л. А. Новикова, С. В. Пискуновой и других ученых. Научную новизну составляет попытка выявления специфики преодоления оппозиций в семиотически сложных текстах, к которым относятся в первую очередь художественные тексты. Новизна обусловлена также недостаточной изученностью проблемы преодоления семантических оппозиций, в том числе в пространстве художественного текста. Практическая значимость результатов исследования состоит в возможности их применения в ходе преподавания вузовских курсов по лексикологии, семантике, семиотике и другим дисциплинам.

В русле идеи текстового семантического поля много работал профессор Л. А. Новиков, в центре внимания которого стояло изучение языка художественной литературы [8]. Согласно его пониманию, в тексте имеются тенденции к трансформации значений языковых единиц в зависимости от взаимодействия разных уровней текста, и вместо языкового поля, соответственно, образуется текстовое поле, под которым понимаются особенные текстовые элементы, объединенные сознанием автора или бессознательно вокруг определенного образа или нескольких образов. Иначе говоря, в процессе исследования текстового семантического поля в семантической структуре текстов обнаруживаются потенциальные возможности для преодоления семантических оппозиций. 
Понятие оппозиции является парадигматическим и заключается в возможности существования или А, или В. При этом парадигматика будет реализована в синтагматике: противопоставления получают особенно важную значимость в «изучении их наиболее характерных “линейных” отношений в тексте» [Там же, с. 555]. А такое изучение существенно способствует пониманию текста и раскрытию его основной идеи. Показательно, что элементы текста, которые входят в одно и то же текстовое семантическое поле, взаимодействуют между собой на разных уровнях текста, что «приводит к порождению авторских единиц и связано с дополнительным развитием семантики и увеличением объема информации» $[9$, с. 685]. Ведь каждый художник слова имеет собственные особенности в употреблении слов и собственную методику творчества, он придает определенным элементам текста особые значения, что отличает его текст от произведений других авторов. Посредством оппозиций устанавливаются внутренние связи между важными для автора элементами, которые проявляются в большей или меньшей степени и в результате которых происходит преодоление семантических оппозиций.

Преодоление оппозиции ярко проявляется в художественном тексте, но принципы организации текстового семантического поля могут быть разнообразными. Рассмотрим принцип организации текстового семантического поля в романах И. С. Тургенева, например в романе «Дворянское гнездо».

Оппозиция серьезный - честный - невинный - чистый - строгий - нежный - милый представлена в контекстах, описывающих Лизу глазами Лаврецкого:

- «Бледное, свежее лицо, глаза и губы такие серьёзные, и взгляд честный и невинный» [11, с. 60].

- «Лаврецкий глядел на ее (Лизы. - В. Н.) чистый, несколько строгий профиль, на закинутье за уши волосы, на нежные шеки, которые загорели у ней, как у ребенка, и думал: "О, как мило стоишь ты над моим прудом!"” [Там же, с. 81].

Очевидно, в настоящем текстовом семантическом поле, тесно связанном с созданием образа Лизы и образуемом различными элементами, преодолеваются оппозиции серьезный, честный и невинный; чистый и строгий, нежный и мильй. Эти элементы участвуют в характеристике образа Лизы, подчеркивают ее отличительные черты (в первую очередь чистоту), выделяющие Лизу на фоне других героинь, и входят в одно текстовое поле именно с помощью импликации. Ведь в общеупотребительном языке мы никогда не будем объяснять серьезный через честный, честный через невинный и т.д.

Благодаря импликации элементов описание передает иногда не один образ, а несколько (два или более), например в оппозиции удар - неожиданный брак - вторичная разлука.

- «Ивану (Ивану Петровичу. - В. Н.) пошел всего двадизатый год, когда этот неожиданный удар (мы говорим о браке княжны, не об ее смерти) над ним разразился» [Там же, с. 30].

- «Бедная жена Ивана Петровича (Маланья Сергеевна. - В. Н.) не перенесла этого удара, не перенесла вторичной разлуки» [Там же, с. 37].

Один и тот же элемент удар, с одной стороны, означает неожиданный брак Глафиры Петровны (для Ивана Петровича), а с другой - вторичную разлуку с сыном (для Маланьи Сергеевны). В результате из этих элементов, у которых нет никакого пересечения в общеупотребительном языке, образуется троичная оппозиция (одно текстовое семантическое поле). Причем в данной оппозиции проявляются отношения импликации и взаимодополнения: если удар, то неожиданный брак; если неожиданный брак, то удар; также происходит с оппозицией удар - вторичная разлука. То есть появляется двусторонняя трактовка явления, которая в дальнейшем раскроется в контексте в соответствии с развитием сюжета. Очевидно, что здесь в оппозицию входят не отдельные элементы, а словосочетания, поскольку сами лексемы удар, брак и разлука не образуют оппозицию как в общеупотребительном употреблении, так и в тексте.

Следует отметить, в текстовом поле не всегда наблюдаются отношения импликации (как в приведенном выше примере), иногда между компонентами текстового поля устанавливаются только периферийные отношения, и в этом случае усиливается функция контекстов. Например, оппозиции: смертельная болезнь кончина - не вставать с постели - погасающие глаза - проститься - обглоданное лицо - с усилием не стало - угаснуть - не мочь говорить - могильные тени - коснеющий язык - умолкнуть навеки умирать - одна и всеми забытая - в последний раз - хладеющие губы. Рассмотрим примеры:

- "Феде еще году не минуло, как Анна Павловна занемогла смертельною болезнью. За несколько дней до кончины, уже не вставая с постели, с робкими слезинками на погасающих глазах, объявила она мужу при духовнике, что желает повидаться и проститься с невесткой» [Там же, с. 35].

- «Потом, обратив обглоданное жестокою болезнью лицо к своему мужу (Анна Павловна. - В. Н.), хотела было заговорить...» [Там же].

- «Анна Павловна с усилием поймала руку мужа и прижалась к ней губами. В тот же вечер ее не стало» [Там же, с. 36].

- «Безропотно, в несколько дней, угасла она. Она уже не могла говорить, уже могильные тени ложились на ее лицо» (о Маланье Сергеевне - В. Н.) [Там же, с. 37].

- «Глаша, Глашка! бульониу, бульониу, старая дур... - пролепетал его (Ивана Петровича. - В. Н.) коснеющий язык $и$, не договорив последнего слова, умолк навеки» [Там же, с. 43].

- «Тот самый образ, к которому старая девица (Глафира Петровна. - В. Н.), умирая одна и всеми забытая, в последний раз приложилась уже хладеющими губами» [Там же, с. 62].

Все данные слова и сочетания транслируют семантику тяжёлой болезни и смерти. Большая их часть передает смысл метафорически, образно, к примеру: обглоданное жестокой болезнью лицо, могильные тени. Кроме того, автор использует эвфемизмы: Анна Павловна не умерла, а ее не стало, Маланья Сергеевна не умерла, а угасла. 
Видно, что выделенные нами фрагменты вместе образуют единое текстовое семантическое поле, которое в основном связано с образами Анны Павловны, Маланьи Сергеевны и Глафиры Петровны. В примерах оппозиции не преодолеваются, элементы находятся лишь на периферии текстового поля и в некоторой степени обусловлены контекстами, вне которых их значения более или менее объяснимы. Причем описываемые события (болезнь и смерть) - это достаточно протяженный, долгий и медленный процесс, что демонстрируют глаголы несовершенного вида вставать, говорить, горевать, умирать, голосить; действительные причастия несовершенного вида коснеющий, погасающий, хладеющий (значительную важную роль играет фонетический повтор звуков $щ$ и ий); деепричастие умирая, словосочетания с усилием и в последний раз. В целом передается мысль о том, что Лаврецкому смерть этих героинь несет не облегчение, а безутешную скорбь.

Дадим данному семантическому полю условное наименование «умирание (завершение жизни)». Но его эмоциональное и оценочное значение может отличаться. Для сопоставления рассмотрим пример:

- «Что это я (Лаврецкий. - В. Н.), - думал он, - жду, как ворон крови, верной вести о смерти жень (Варвары Павловны. - В. Н.)!» [Там же, с. 98].

Здесь выражение ждать, как ворон крови означает мысль Лаврецкого о том, что смерть Варвары Павловны будет для него радостью, и его ужас по поводу этой мысли.

Обратим внимание также на то, что в приведённых фрагментах текста практически отсутствует само слово смерть, но данная семантика передаётся с помощью разнообразных компонентов: смертельная болезнь, кончина, коснеющий, погасающий, в последний раз, не стало и т.д. При этом слово смерть встречается там, где значение прощания с жизнью вообще отсутствует. Например: пудриться - смерть - мука - умереть поделиться властью.

- «Она ни во что не вмешивалась, радушно принимала гостей и охотно сама выезжала, хотя пудриться, по ее словам, было для нее смертью... а в гости без пудры нельзя - обидятся, - мука!» (о прабабке Лаврецкого - Анне Павловне - В. Н.) [Там же, с. 29].

- «Гафира скорее согласилась бы умереть, чем поделиться властью с другой хозяйкой, - и какою еще хозяйкой!» (о Глафире Петровне - В. Н.) [Там же, с. 36].

Из контекстов хорошо видно, что для Анны Павловны пудра ассоциируется со смертью и мукой, а для Глафиры Петровны смерти (умереть) равносильна возможность разделения с кем-то власти. То есть лексемы смерть и умереть употребляются в переносном и гиперболическом значениях, их смысл связан с передачей автором категорического нежелания героинь что-то делать. Само собой разумеется, что в данном поле противоположный смерти полюс (семантическая оппозиция) не жизнь, как в общеупотребительном языке, а возможность не пудриться и обладать властью. Эти элементы не образуют текстовое поле, а только создают характеристики обеих героинь и передают их нежелание, проявляемое в высокой степени, 'очень, сильно'.

Преодоление семантических оппозиций также можно отметить в полифоническом тексте романа Ф. М. Достоевского «Идиот», в котором один и тот же элемент идиот привлекает к себе в текстовое поле одновременно несколько элементов: «умный - глупый, хитрый - наивный, доверчивый - расчетливый» [4, с. 61-75]. Лексически это проявляется с помощью выражений такая невинность, слишком невинный/умный, всетаки умный, ужасно наивный, совершенное дитя, точно/почти как ребенок, вполне ребенок, совсем (почти) идиот, в самом деле идиот, по крайней мере искренний, безграничная доверчивость, до того простодушный и др. Такие характеристики главного героя романа встречаются как в репликах других персонажей, так и в его собственных:

- «Частые припадки его болезни сделали из него совсем почти идиота» [5, с. 26].

- «Он сказал мне, что он вполне убедился, что я сам совершенный ребенок, то есть вполне ребенок...» [Там же, с. 72].

В составе данных выражений особенно значимы единицы, обозначающие высокую степень качества, - частицы, качественные прилагательные, наречия степени и др., - с помощью которых вроде бы разные сочетания объединяются в единое текстовое поле. В условиях полифонии особенно важен контекст: сочетания слов устраняют любые логические ограничения, иначе говоря, может быть «сколь угодно обширный спектр значений» [2, с. 115]. Как отмечает О. И. Валентинова, которая много внимания уделила изучению творчества Ф. М. Достоевского, «полифония стремится к равномерной актуализации смыслов, в том числе противоположных и взаимоисключающих друг друга» [3, с. 14], поэтому в текстовые семантические поля вовлекаются компоненты с каким-то единственным семантически общим элементом, обусловливающим похожесть на другие единицы.

Итак, в семиотически сложных текстах, к которым относятся художественные тексты, действительно происходит преодоление семантических оппозиций. При этом языковые единицы, входящие в различные сочетания и выражения, представленные в контексте, начинают служить пониманию главного смысла произведения, раскрытию его идеи. Они развиваются семантически, и художественный текст становится более информативным с точки зрения выражаемых им содержания, оценок, эмоций. Наиболее яркое проявление данного явления наблюдается в полифоническом художественном тексте, где элементы, которые входят в одно и то же текстовое семантическое поле, могут быть максимально разнообразными. Элементы, которые могут быть не связаны в общеупотребительном языке, в контексте взаимно дополняют друг друга, трансформируя свою семантику без каких-либо логических ограничений. Как следствие, в художественном тексте наблюдаются отношения импликации, и в результате преодоления семантических оппозиций формируются неповторимые индивидуальные текстовые семантические поля. В зависимости от контекста на их особенности может влиять специфика конкретного художественного текста, как это происходит в романах И. С. Тургенева «Дворянское гнездо» и Ф. М. Достоевского «Идиот». Семантические оппозиции и текстовые поля здесь формируются под влиянием сознания автора или бессознательно. Ведь цель художника слова - передать в тексте 
своё я, воссоздать в вербальной форме собственный поток сознания. В результате в созданных индивидуальных неповторимых единичных текстовых семантических полях всегда больше бессознательного, чем осознанного. Дальнейшие исследования могут вестись в направлении привлечения к анализу новых типов семиотически сложных текстов. Кроме того, необходимо расширить текстовую базу исследований художественного текста за счёт произведений современных писателей.

Список источников

1. Архипова С. А., Буянова Л. Ю. Семиотика мимического и окулистического жеста в художественном тексте (на материале произведений Л. Н. Толстого) // Актуальные проблемы языкознания: сб. науч. ст. Краснодар: КубГУ, 2017. С. 3-8.

2. Валентинова О. И. Основные принципы построения концептуального словаря полифоничного текста // Вестник Российского университета дружбы народов. Серия «Лингвистика». 2006. № 8. С. 115-126.

3. Валентинова О. И. Семиотика полифонии: монография. М.: Изд-во РУДН, 2005. 259 с.

4. Валентинова О. И. Универсальные принципы анализа вербального искусства: учебное пособие. М.: РУДН, 2010.158 с.

5. Достоевский Ф. М. Идиот. М.: Эксмо, 2016. 640 с.

6. Крылова М. Н. Символика Китая в современной русской литературе // Критика и семиотика. 2016. № 1. С. 227-235.

7. Лотман Ю. М. Текст в тексте // Ученые записки Тартуского государственного университета. 1981. Вып. 567. С. 3-18.

8. Новиков Л. А. Эскиз семантического поля // Новиков Л. А. Избранные труды: в 2-х т. М.: Изд-во РУДН, 2001. Т. 2. Эстетические аспекты языка. Miscellanea. С. 554-570.

9. Пискунова С. В. Нейтрализация семантических оппозиций в поэтическом тексте // Вестник Тамбовского университета. Серия «Гуманитарные науки». 2011. № 12 (104). С. 684-689.

10. Садченко В. Т. Текст как объект лингвистической семиотики // Вестник Челябинского государственного университета. 2009. № 5 (143). С. 104-111.

11. Тургенев И. С. Полное собрание сочинений и писем: в 30-ти т. / гл. ред. М. П. Алексеев. М.: Наука, 1981. Т. 6. Дворянское гнездо. Накануне. Первая любовь. 1858-1860. 495 с.

12. Химич Г. А. К вопросу о философии и семиотике художественного текста // Вестник Российского университета дружбы народов. Серия «Теория языка. Семиотика. Семантика». 2010. № 2. С. 33-40.

\title{
Overcoming Semantic Oppositions in Semiotically Complicated Fiction Texts
}

\author{
Wang Na \\ Peoples' Friendship University of Russia, Moscow \\ helenvanna@yandex.ru
}

\begin{abstract}
The article aims to examine the phenomenon of semantic opposition, to analyse examples of overcoming semantic oppositions in a fiction text and to identify the means of forming the textual semantic field. Scientific originality of the study involves identifying the ways to overcome semantic oppositions in semiotically complicated texts. The conducted research allows concluding that while overcoming semantic oppositions, unique textual semantic fields are formed, both intentionally and spontaneously. Overcoming semantic oppositions aims to clarify the meaning of a work of fiction, to reveal its idea, to increase its meaningful and emotional informative content.
\end{abstract}

Key words and phrases: semantic opposition; overcoming opposition; textual semantic field; semiotically complicated text; fiction text.

УДК $81-114.2$

https://doi.org/10.30853/filnauki.2020.5.25

Дата поступления рукописи: 02.03.2020

Цель исследования - выявить особенности выражения категории оценки во фразеологии русского языка. Научную новизну работы определяет изучение способов проявления оценочного значения на материале особого лексико-грамматического разряда предикативно-оценочных фразеологических единиц. Полученные результаты показали, что необходимо выработать новые методы и приемы изучения категории оченки в языке. Одним из перспективных приемов в данном направлении является анализ семантики фразеологических единии исследуемого разряда с учетом их употребления в языковом контексте.

Ключевые слова и фразы: категория оценки; русский язык; семантика; фразеология; лексико-грамматический разряд фразеологизмов; предикативно-оценочные фразеологические единицы.

Верзилова Арина Александровна

Ивановский государственньй университет

arinaver_1991@mail.ru

\section{Категория оценки в идиоматике русского языка}

В процессе познания человеком окружающей действительности постепенно формировались представления о наиболее общих категориях, отражающих наше видение действительности: время, пространство, состояние, количество и др. Научное осмысление этих категорий происходит постепенно, по мере осознания их сути. В ходе этого процесса выявляются новые категории, возникает необходимость их специального исследования. К таким категориям относится и категория оценки. 